\title{
Transferability of Voice Communication in Games to Virtual Teams Training for Crisis Management
}

Jan Rudinsky, University of Iceland, Reykjavik, Iceland

Ebba Thora Hvannberg, University of Iceland, Reykjavik, Iceland

\begin{abstract}
A crisis is an emergency event that can lead to multiple injuries and damage to property or environment. Proper training of crisis management personnel is vital for reducing the impact of a major incident. In search for knowledge on how best to implement communication for virtual environments for training, communication in online games was studied. Findings on voice communication in online games were researched and formulated as a set of statements. By asking participants in an empirical study of crisis management, the statements were either confirmed or refuted. Results show that multiplayer games are highly similar to the requirements for crisis management training in virtual environments. Approximately two-thirds of the statements proved coherent in both domains. The practical significance of this work lies in the provision of design implications for a virtual environment for crisis management training. Thus, this paper contributes to demonstrating the transferability between these domains. Finally, the paper reflects the results in theories of communication and engagement.
\end{abstract}

\section{KEYWORDS}

Avatar Behaviour, Broadcasts, Design Guidelines, Empirical Studies, Groups, Mobile Learning, Online Multiplayer Games, Phone, Radio, Validation, Virtual Environments

\section{INTRODUCTION}

A crisis is an emergency event that can lead to multiple serious or fatal injuries and can cause structural failure or damage to a property. A plane crash, an explosion or a fire at an airport are examples of such events in the aviation sector. To minimise personal injury and limit damage, any such emergency situation should activate a rapid and well-organised crisis management response. In scale and complexity, crisis events far exceed the cognitive and communicative resources of an individual (Greef \& Arciszewski, 2007). Therefore, the response to a crisis must be managed by persons who are organised in teams that belong to emergency services such as Rescue and Fire fighters, Police or Paramedics. During crisis events information is provided in face-to-face conversation or by telecommunication channels, including radio and telephone systems and multimodal information technology. 
Communication and data flow between team members, e.g. first responders and commanders, is paramount and plays a crucial role through all levels of coordination (Cooke, Gorman, Myers, \& Duran, 2013). A coordination structure is based on effective communication and must be deployed to drive the operation into the successful recovery of a normal situation. Examples of communication in crisis management include reports about incident scale and progress, requests for resources or information and task delegation. First responders and commanders on the scene share this information with each other and with remote command centres. Research has shown that training teams in communication skills and strategies can help them overcome hindrances in coordination (Salas, Cooke, \& Rosen, 2008) but to achieve good team performance the communication training needs to be carefully designed (see (Adelman, Christian, Gualtieri, \& Bresnick, 1998) and a meta-analysis of which factors improve team performance (Salas, DiazGranados, et al., 2008)) and that the design of technology needs to be founded in the needs and abilities of teams (Salas, Cooke, et al., 2008).

Motivated by the need for training of communication during crisis management, where the use of heterogeneous media and the requirement of reliable information delivery in crisis management is emphasised, we aimed to investigate the design of communication in a virtual training environment for crisis managers and first responders. Because real-life training for crisis management is expensive due to its complexity, temporal criticality and demands for resources, training in a virtual environment can be a favourable option. Predecessors of virtual environments were so called micro worlds that have been used for simulations and training (Brehmer \& Dörner, 1993). Previous results of training in virtual environments have been obtained in domains such as crisis communication, decision making and emergency response (Haferkamp, Kraemer, Linehan, \& Schembri, 2011), resource management (Heinrichs, Youngblood, Harter, \& Dev, 2008), medical education (Creutzfeldt, Hedman, Medin, Heinrichs, \& Felländer-Tsai, 2010; Grantcharov et al., 2004; Wiecha, Heyden, Sternthal, \& Merialdi, 2010) and training airport emergency plans (Zarraonandia, Vargas, Díaz, \& Aedo, 2009). However, reviews of the state of the art of virtual laboratories for education reveals that while communication and collaboration is one of four design criteria of virtual systems, only a few projects have fulfilled it completely (Potkonjak et al., 2016).

Virtual environments have been significantly influenced by online game technology during the past few years. Originally, developed for the purpose of amusement and recreation, games now offer training and educational opportunities, often termed serious games (Crookall, 2010). The evolution of gaming from a single player to an online multiplayer experience provides an opportunity to train for crisis management in a virtual environment. To enhance their chances of achieving a goal, players of multiplayer online games and crisis managers prefer to exchange information. In games, two modes of communication are normally used, text and voice. Typed text has been the traditional medium of communication, but the use of voice is on the rise, because speaking is a natural form of communication; speaking is faster than typing and allows for simultaneous use with other game interfaces such as a mouse or a keyboard (Wadley, 2011; Wadley, Gibbs, \& Benda, 2005).

The purpose of this research was to exploit findings on communication in online games in the literature and life observations of crisis training to create guidelines for design of communication interfaces in a virtual training environment. We wanted to take advantage of the knowledge developed in games research, or what has been termed gamification by Deterding, Dixon, Khaled, and Nacke (2011), as "the use of game design elements in non-game contexts". The methodology applied in this study is depicted in Figure 1. We looked for findings on voice communication in online games in the literature and formulated as a set of statements. After inquiring about the experience of participants and observing their work practices in an empirical study of crisis management communication, the statements were validated. The results were used to create design guidelines for communication interface, usable for the development of Crisis Management Training (CMT) in a virtual environment. We will show that these guidelines can be applied in developing training systems in other safety critical domains. A secondary result of this study is how well findings on voice communication in online games fit for crisis management training in virtual environment. 


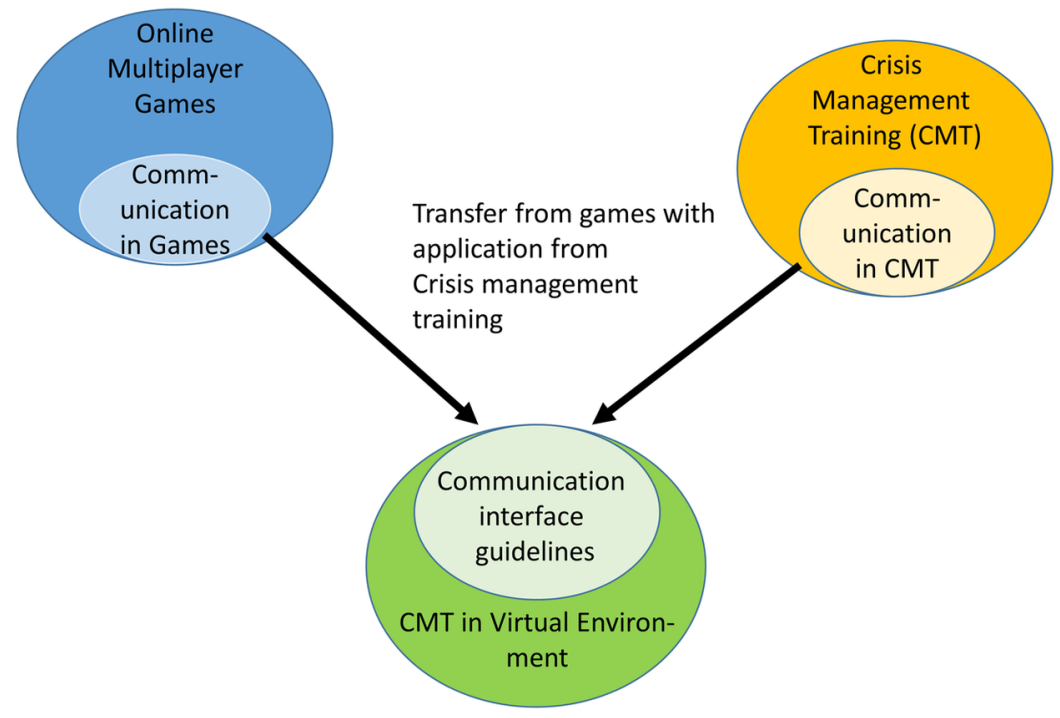

\section{BACKGROUND}

\section{Safety-Critical Communication}

One of the required components of crisis management is effective communication that must ensure reliable information delivery to the appropriate destination, carrying clear content with a satisfactory level of detail. In this respect, previous research addresses information exchange, media, and the repercussions of problems in communication.

Reliable information exchange is a significant activity for safety-critical communication. A study in the aviation domain showed that approximately three quarters of the errors on information exchange that were reported and assessed for situation awareness resulted from a failure to perceive information correctly; one-fifth of the errors were because of failing to fully comprehend a situation and only three percent of the errors were related to the projection of a future situation (Jones \& Endsley, 1996). This model of situation awareness consisting of perception, comprehension and projection is a fundamental one for system design, but it needs to be expanded to include team situation awareness. Although most of the research on situation awareness has been conducted in the area of aviation, it has spread to other domains, which then prompts addressing unique situational awareness challenges (Endsley \& Jones, 2013).

The use of different media and their impact on work has been studied in the literature. In the theory of communications grounding, Clark and Brennan (1991) introduced characteristics of different media and described their influence on information delivery and understanding. These media characteristics and their importance for safety-critical communications were evaluated in a field study of communication in the oil-drilling industry (Bayerl \& Lauche, 2010). The study showed that compared to media like phone, e-mail and audio, more recently adopted ICT media, such as video and desktop sharing, did not have a radical impact on team coordination, but resulted in modification and adaptation of existing routines.

Problems in communication can have various implications for team performance. A field study and literature research (Bharosa, Lee, \& Janssen, 2010) found that a lack of information sharing among response agencies can cause major problems such as a negative influence on collective decision-making and the coordination of action. The results showed that problems occur at all levels of coordination (individual, team, and agency), and thus, they must be tackled at these levels 
simultaneously. A descriptive study of the challenges of communication in emergency response (Manoj $\&$ Baker, 2007) identified three problem types: 1) technological challenges, such as rapid deployment of a communication system or multi-agency interoperability; 2) sociological challenges, including the sharing of information or the lack of a common vocabulary; and 3) organisational challenges that vary with respect to changes between hierarchical, flat or hybrid organisations. We will address these again in the discussion of the results.

\section{Crisis Management Training}

Training provides the opportunity to evaluate options, while a lack of training will cause delays with negative consequences for casualties in a real-life situation. Training should expose responders to a range of situations that are based on potential scenarios that could occur in their jurisdiction. People who learn how to solve a complex situation during a training exercise can respond more efficiently during a real-life event compared to those without the training (Jain \& McLean, 2005; Klein, 1993).

The ability of teams to coordinate their actions effectively determines the success of crisis management (Toups, Kerne, \& Hamilton, 2011). Security, medical, rescue and fire-fighting teams that are deployed at the site of an incident have different professional backgrounds and have varying skills that are acquired in individual and team training. Therefore, in inter-team training responder teams could develop similar mental models, allowing emergency managers to establish comparable approaches towards the teams and towards responders within the teams. Coordination of skills that should be taught include information exchange, decision making, causal analysis and prediction of situation development. Training in communications is fundamental to the training of coordination skills.

A valuable training method for emergency preparedness in the aviation sector is a fullscale exercise. A large-scale, multi-agency, real-life exercise improves crisis coordination and communication in close-to-real environment training conditions and results in thorough preparation across professional domains. However, the exercise requires a considerable number of personnel and substantial organisational complexity, which imply significant financial and temporal demands. Such an exercise is typically carried out every two years in the aviation sector, but because of a lack of resources the interval can be almost doubled. While a large-scale exercise can yield credible results, a subset of the required skills can be obtained by performing a simpler table-top exercise. Such an exercise requires only the team commanders' participation and less preparation time and resources, and it provides the advantage of testing hypothetical situations without causing disruption in the community. Typically, every year, airport crisis management trains in such exercises. Because of the complexity and cost of comprehensive real-life training, the most frequent training method to date is an individual exercise, comprising several subtasks, that does not require coordination with others and which a trainee repeatedly practices to solidify emergency response skills.

\section{Training in a Virtual Environment}

With the fast development of virtual environment technology, especially in the gaming industry, a number of opportunities have arisen to exploit it for training. A digital game that is designed with the intent of learning and entertaining has been termed a serious game (Johnston \& Whitehead, 2009; Zyda, 2005). Boyle et al. (2016) have done a systematic literature review of the impacts and outcomes of serious games. Their results show that positive impact of serious games is increasing. The study concluded that games mainly support knowledge acquisition, although some examples could be seen where games support skill acquisition or collaborative interactions. It is likely that before games can support training of these skills, we will need further research on instruments that support communication.

Training in a virtual environment can reduce the costs to one-tenth compared to live exercises (Jain \& McLean, 2005). A trainee in a virtual environment is allowed to train more frequently during a time that is suitable for his or her work, and trainees who are distributed in distant geographical 
locations can still cooperate in a collaborative training environment. Most importantly, the use of virtual environments allows responders to gain experiences from many different scenarios. They can be easily prepared based on a template and later reused without the need to organise resources, such as in a real-life exercise. In turn, a virtual environment will significantly shorten the preparation time and expand emergency preparedness. Finally, a virtual environment has the possibility of real-time observation of multiple trainees, which makes the after-action review and debriefing fast and accurate.

\section{RESEARCH METHODS}

As mentioned in the introduction, the research study had two parts. First, we collected data from the crisis management area and how it is practiced. The next subsection describes how this data was collected. Second, we derived knowledge about communication in online games and formulated statements from the literature. The second subsection describes the literature analysis and how the groups of statements were derived. Third, we used the data collected from crisis management to validate the statements derived in observation of crisis management training to learn whether they could be valuable for developing a CMT system. The research process is described in Figure 2.

\section{Data Collection}

Data on how crises are managed were collected from three European Incident Command Systems (ICS) over a period of nine months. Three examples of crises were provided, as described in Table 1. Four rounds of data collection were conducted to learn about crisis incidents, roles, tasks, procedures,

Figure 2. Study process - data collection and analysis

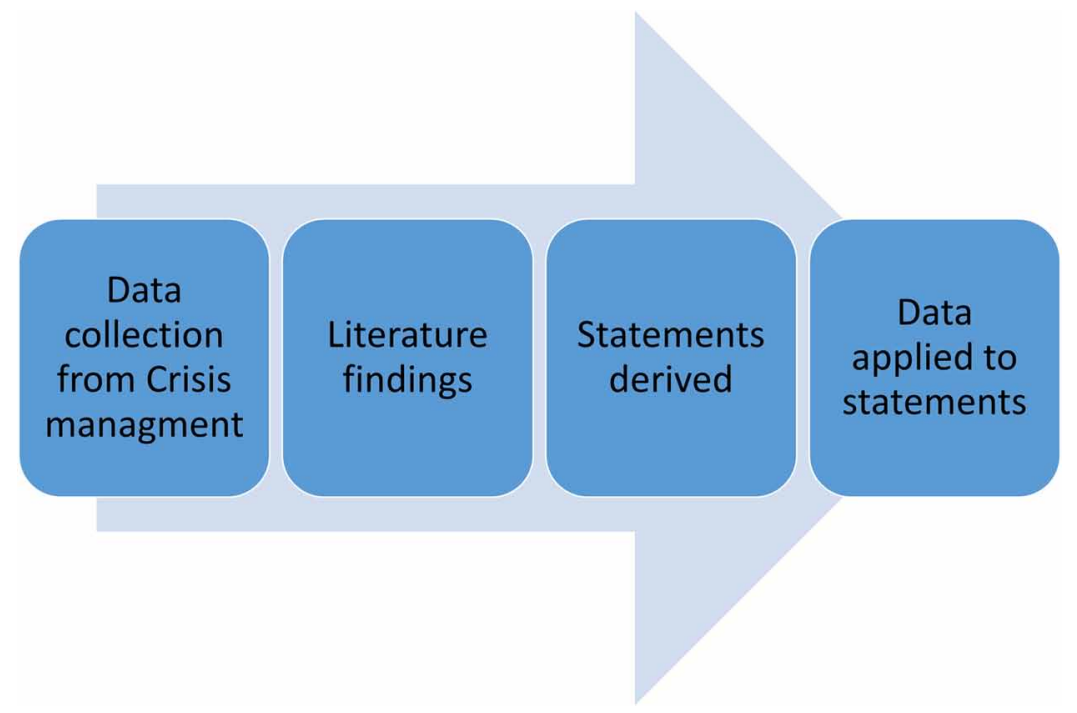

Table 1. Crisis examples

\begin{tabular}{|l|l|}
\hline \multicolumn{1}{|c|}{ Incident } & \multicolumn{1}{c|}{ Description } \\
\hline Aircraft incident & An aircraft accident when engine failure caused a crash landing at an airport \\
\hline Bomb threat & A deliberate incident of a bomb explosion in an airport building \\
\hline Train crash & A train and vehicle collision at a railway crossing due to faulty signaling \\
\hline
\end{tabular}


artefacts and contexts at the three sites. The data collection instruments used included site visits, elicitation workshops, observations of training exercises and end-user sessions.

During initial site visits, crisis training managers of each ICS introduced a command and a coordination structure and provided an overview of procedures, roles, their responsibilities, physical contexts and current training methods. The data were elicited during site visits to airports, train stations and emergency response agencies.

The second round of data elicitation was held at all three sites, comprising informal discussions and semi-structured interviews with crisis management personnel across field and all command levels. There were 38 participants with roles ranging from a first responder to a national commander. Workshop discussions lasted approximately an hour and were followed by semi-structured interviews that lasted up to three hours. The interviews recordings contained a description of specific roles and their responsibilities, participants' experiences from real-life incidents and training that took place.

Two types of crisis management training sessions were observed in the third round of data elicitation at one of the sites. The first was a table-top exercise that used a simulated scenario (i.e. an aircraft incident), allowing crisis managers to train for communication and coordination. We observed two table-top exercises, each lasting approximately one hour.

The second type of training session was a large-scale, multi-agency, live training exercise that took place in a small rural airport. The training session involved approximately fifty participants across four different emergency response agencies (fire fighters, ambulance, police and volunteers acting as casualties). The data described the physical context of the crisis management, including environments and artefacts, and the social context, such as the interaction between people in different roles and their coordination. Further information was solicited in semi-structured interviews with the exercise participants. Three persons provided their own experience, which represented multiple roles, ranging from a first responder to an on-scene commander. Thirty-four interview questions were organised into groups of current practices in crisis management, verbal communication, and problems encountered during communication.

Informal discussions and semi-structured interviews were a part of the third round of elicitation which was conducted with the crisis training managers at all three sites and took half a day at each site.

To better understand the roles of agencies during crisis management, a set of procedures and manuals about the incident command systems was collected. The documents provided additional information about the command structure and overall agency roles and responsibilities. Table 2 gives an overview of the instruments and materials that were collected at each event and incident type.

\section{Derived Statements from Online Game Research}

To review research results on communication in online games, we searched ACM, IEEE and Springer digital libraries with the keywords voice and communication in combination with video games, serious games and collaborative virtual environment. After an analysis of the retrieved papers, several subtopics of communication emerged that were organised into seven groups relevant to communication in virtual environments. These groups are Media richness selection, Groups of people, Identities of people, Avatar behaviour, Learning, Trust and the Problem group. The main ideas were consolidated within each group and formulated into statements that we attempted to verify from the crisis management perspective (see next section).

We refined the set of statements by selecting only the statements that had the following characteristics: 1) Applicable to crisis management or to training, 2) Reliable and backed by multiple references, and 3) Validated easily by empirical data. A simple scoring method was applied, in which each of the above-mentioned characteristics resulted in the corresponding statement earning one point. Ten statements, those with the highest scores, were selected from the 19 original statements and are identified with a number in the last column, as shown in Table 3. All except one of the seven groups were retained, but the group Trust did not contain any statements after the validation. 
Table 2. Material collected from stakeholders for each incident case

\begin{tabular}{|c|c|c|c|c|c|}
\hline \multirow{2}{*}{ Source } & \multicolumn{2}{|c|}{ Participants } & \multirow{2}{*}{ Method } & \multirow{2}{*}{$\begin{array}{l}\text { Collected } \\
\text { Data }\end{array}$} & \multirow{2}{*}{ Data Content } \\
\hline & Role & Agency & & & \\
\hline \multirow{3}{*}{ Site visits } & \multirow{3}{*}{$\begin{array}{l}\text { Crisis } \\
\text { managers }\end{array}$} & \multirow{2}{*}{$\begin{array}{l}\text { Airport } \\
\text { operators }\end{array}$} & Presentation & Presentation & \multirow{3}{*}{$\begin{array}{l}\text { Crisis organisation } \\
\text { structure, procedures. } \\
\text { Introduction to: } \\
\text { roles, resources, } \\
\text { responsibilities, physical } \\
\text { context, current training }\end{array}$} \\
\hline & & & Discussion & $\begin{array}{l}\text { Interview } \\
\text { recordings }\end{array}$ & \\
\hline & & $\begin{array}{l}\text { Railways police } \\
\text { force }\end{array}$ & $\begin{array}{l}\text { Unstructured } \\
\text { interview }\end{array}$ & Notes & \\
\hline \multirow{2}{*}{$\begin{array}{l}\text { Elicitation } \\
\text { workshop }\end{array}$} & $\begin{array}{l}\text { First } \\
\text { responders }\end{array}$ & $\begin{array}{l}\text { Police force Fire } \\
\text { fighters }\end{array}$ & Discussion & $\begin{array}{l}\text { Discussion } \\
\text { recordings }\end{array}$ & \multirow{2}{*}{$\begin{array}{l}\text { Roles and } \\
\text { responsibilities. Real-life } \\
\text { training and experiences } \\
\text { (partial focus on } \\
\text { communication) }\end{array}$} \\
\hline & Commanders & $\begin{array}{l}\text { Medical service } \\
\text { Search and } \\
\text { Rescue }\end{array}$ & $\begin{array}{l}\text { Semi-structured } \\
\text { interview }\end{array}$ & $\begin{array}{l}\text { Interview } \\
\text { transcripts }\end{array}$ & \\
\hline \multirow{5}{*}{ Observation } & \multirow{2}{*}{$\begin{array}{l}\text { First } \\
\text { responders }\end{array}$} & Police force & \multirow{5}{*}{$\begin{array}{l}\text { Observations } \\
\text { of: real-life, } \\
\text { exercise, table- } \\
\text { top exercise } \\
\text { and emergency } \\
\text { service premises }\end{array}$} & \multirow[b]{2}{*}{ Videos } & \multirow{5}{*}{$\begin{array}{l}\text { Physical context: } \\
\text { environment, resources. } \\
\text { Social context: roles, } \\
\text { interaction and } \\
\text { coordination. Training } \\
\text { prep. } \\
\text { and evaluation }\end{array}$} \\
\hline & & $\begin{array}{l}\text { Fire fighters } \\
\text { Medical service }\end{array}$ & & & \\
\hline & \multirow{3}{*}{ Commanders } & $\begin{array}{l}\text { Search and } \\
\text { Rescue }\end{array}$ & & \multirow{3}{*}{ Photos } & \\
\hline & & $\begin{array}{l}\text { Emergency } \\
\text { centre }(112 \\
\text { /911) }\end{array}$ & & & \\
\hline & & $\begin{array}{l}\text { Airport operator } \\
\text { Civil Protection }\end{array}$ & & & \\
\hline \multirow{2}{*}{ Interviews } & $\begin{array}{l}\text { First } \\
\text { responders }\end{array}$ & $\begin{array}{l}\text { Police force Fire } \\
\text { fighters }\end{array}$ & \multirow{2}{*}{$\begin{array}{l}\text { Structured } \\
\text { interview }\end{array}$} & \multirow{2}{*}{$\begin{array}{l}\text { Interview } \\
\text { recordings }\end{array}$} & \multirow{2}{*}{$\begin{array}{l}\text { Roles and } \\
\text { responsibilities (focus on } \\
\text { communication) }\end{array}$} \\
\hline & Commanders & $\begin{array}{l}\text { Search and } \\
\text { Rescue }\end{array}$ & & & \\
\hline \multirow{2}{*}{$\begin{array}{l}\text { Evaluation } \\
\text { session }\end{array}$} & \multirow{2}{*}{$\begin{array}{l}\text { Crisis } \\
\text { managers }\end{array}$} & $\begin{array}{l}\text { Airport } \\
\text { operators }\end{array}$ & \multirow{2}{*}{$\begin{array}{l}\text { Semi-structured } \\
\text { interview }\end{array}$} & \multirow{2}{*}{$\begin{array}{l}\text { Interview } \\
\text { transcripts }\end{array}$} & \multirow{2}{*}{$\begin{array}{l}\text { Verification of details } \\
\text { of: roles, responsibility, } \\
\text { environment, } \\
\text { communication }\end{array}$} \\
\hline & & $\begin{array}{l}\text { Railways police } \\
\text { force }\end{array}$ & & & \\
\hline \multirow[b]{2}{*}{ Manuals } & & \multirow{2}{*}{$\begin{array}{l}\text { Airport } \\
\text { operators, } \\
\text { Railways police } \\
\text { force }\end{array}$} & & \multirow[b]{2}{*}{$\begin{array}{l}\text { Emergency } \\
\text { plans }\end{array}$} & \multirow{2}{*}{$\begin{array}{l}\text { Roles, procedures, } \\
\text { tasks (partial focus on } \\
\text { communication) }\end{array}$} \\
\hline & & & & & \\
\hline
\end{tabular}

\section{RESULTS}

The data collected during the elicitation of requirements to the crisis management training environment were used to verify the statements derived in the previous section. The data were analysed for validity of the statements using the following criteria:

- Do the data support or refute the statement?

- Do the data call for modifying or creating a new statement?

- If the statement is refuted, can it be explained by differences in the two domains, games and crisis management training? 
Table 3. Statement selection based on: Applicability (A), Reliability (R) and Validity (V)

\begin{tabular}{|c|c|c|c|c|c|}
\hline \multirow{2}{*}{ Group / Statements } & \multicolumn{4}{|c|}{ Score } & \multirow{2}{*}{$\begin{array}{l}\text { Statement } \\
\text { No. }\end{array}$} \\
\hline & $\mathbf{A}$ & $\mathbf{R}$ & $\mathbf{V}$ & Sum of Scores & \\
\hline \multicolumn{6}{|l|}{ Media Richness Selection } \\
\hline $\begin{array}{l}\text { The social richness of the communication medium must be matched with the task } \\
\text { characteristics (urgency of the task or cues necessary to perform the task), fellow } \\
\text { communicators (number of communicators, their preferences and their required presence) } \\
\text { and a person's organisation or users' prior experience with the medium (Sallnäs, 2002; } \\
\text { Tan, Tan, \& Teo, 2012; Wadley, Gibbs, \& Benda, 2007). }\end{array}$ & 1 & 1 & 1 & 3 & 1. \\
\hline $\begin{array}{l}\text { Leaner medium (e.g. text) can cause impulsive or reserved behaviour, but can be used } \\
\text { as a medium for initial contact (e.g. with unknown participants) or for asynchronous } \\
\text { communication that allows easy information processing (e.g. search in conversation } \\
\text { history) (Halloran, Rogers, \& Fitzpatrick, 2003; Wadley et al., 2007; Wadley, Gibbs, \& } \\
\text { Ducheneaut, 2009) }\end{array}$ & 1 & 1 & 0 & 2 & 2. \\
\hline $\begin{array}{l}\text { Currently, there are four metaphors for designing voice channels in games: broadcasting, } \\
\text { landline, mobile phone, and proximity voice chat (Wadley et al., 2005). }\end{array}$ & 1 & 0 & 1 & 3 & 3. \\
\hline $\begin{array}{l}\text { Solving tasks (e.g. making a decision) through } \mathrm{CMC} \text { takes twice as long as F2F but } \\
\text { with half of the utterances and gives the same result. However, in F2F, socio-emotional } \\
\text { functions are more frequent (as well as with voice compared to text), which has a negative } \\
\text { impact on group effectiveness ( } \mathrm{Li}, 2007) \text {. }\end{array}$ & 1 & 0 & 0 & 1 & - \\
\hline $\begin{array}{l}\text { Voice compared to text communication improves performance and social experience. } \\
\text { Video does not add significant advantages to task performance compared to audio, but } \\
\text { video supports informal communication and relation building (Sallnäs, 2002). }\end{array}$ & 1 & 0 & 0 & 1 & - \\
\hline $\begin{array}{l}\text { Preference for anonymity is one of the main reasons that is cited by Second Life users for } \\
\text { rejecting voice (Wadley et al., 2009). }\end{array}$ & 1 & 0 & 0 & 1 & - \\
\hline $\begin{array}{l}\text { Using verbal communication, especially real voice, can break the sense of immersion in a } \\
\text { game (Bartle, 2003). }\end{array}$ & 1 & 0 & 0 & 1 & - \\
\hline \multicolumn{6}{|l|}{ Groups of people (players/trainees) } \\
\hline $\begin{array}{l}\text { Voice communication that simulates a radio channel is most useful for a small group of } \\
\text { players (6-10) who know each other and are playing a fast-paced game, to coordinate } \\
\text { their tactics (issue directions, call for help) and achieve a goal while moving around a } \\
\text { geographical area. However, as players reported, the use of multi-channels can cause } \\
\text { fragmentation of the party into sub-teams (Raybourn, 2007; Wadley et al., 2007). Voice } \\
\text { does not scale well to large groups (Wadley, Carter, \& Gibbs, 2015) }\end{array}$ & 1 & 1 & 1 & 3 & 4. \\
\hline $\begin{array}{l}\text { Proximity voice chat, which is a virtual metaphor for face-to-face in the real world, may } \\
\text { be necessary where a large number of players would clutter a shared radio channel, } \\
\text { players are close to each other in the virtual environment, and the benefit of cues that } \\
\text { indicate which direction a sound is travelling from outweighs the inability to speak with } \\
\text { distant players (Gibbs, Wadley, \& Benda, 2006). Proximity chat enables enjoyable game } \\
\text { play experiences and user interactions (Carter, Wadley, \& Gibbs, 2012) }\end{array}$ & 1 & 0 & 1 & 2 & 5. \\
\hline $\begin{array}{l}\text { The proximity of other players' avatars is the most useful learning aid for the less } \\
\text { experienced gamer, who could follow their actions and speech to find out how the game } \\
\text { works (Halloran et al., 2003). }\end{array}$ & 1 & 0 & 0 & 1 & - \\
\hline \multicolumn{6}{|l|}{ Identity of people (players/trainees) } \\
\hline $\begin{array}{l}\text { Players engaged in a virtual environment had difficulty identifying who was speaking, } \\
\text { determining who could hear what they said and knowing whether it was heard at all. } \\
\text { Players reported that the voice channel had inadequate facilities to control what was } \\
\text { heard and what was sent and that it introduced delay. As a result, it can inhibit convivial } \\
\text { computer-mediated social interaction (Gibbs, Hew, \& Wadley, 2004; Gibbs et al., 2006; } \\
\text { Wadley et al., 2009). Voice reveals identity better than text which makes it more sociable } \\
\text { but can interfere role-play and pseudonymity (Wadley et al., 2015). }\end{array}$ & 1 & 1 & 1 & 3 & 6. \\
\hline $\begin{array}{l}\text { Not knowing who is talking in a distributed player setting can have a negative effect on } \\
\text { learning and coordination in team-based war games (more/longer utterances to find out } \\
\text { who is present, what is their level of skills or to address the person). On the other hand, } \\
\text { knowing a partner results in fair decision making (Halloran, Fitzpatrick, Rogers, \& } \\
\text { Marshall, 2004; Halloran et al., 2003; Yamamori, Kato, Kawagoe, \& Matsui, 2008). }\end{array}$ & 1 & 1 & 0 & 2 & 7. \\
\hline
\end{tabular}




\begin{tabular}{|c|c|c|c|c|c|}
\hline \multirow{2}{*}{ Group / Statements } & \multicolumn{4}{|c|}{ Score } & \multirow{2}{*}{$\begin{array}{c}\text { Statement } \\
\text { No. }\end{array}$} \\
\hline & $\mathbf{A}$ & $\mathbf{R}$ & $\mathbf{V}$ & Sum of Scores & \\
\hline \multicolumn{6}{|l|}{ Avatar behaviour } \\
\hline $\begin{array}{l}\text { Where visual representation is available (e.g. videoconference, collaborative virtual } \\
\text { environment), verbal actions should be coupled with postural, gestural and proximity } \\
\text { information of the player embodiment. This information can help identify the speaker and } \\
\text { can increase communication during participants' performances (Cassell \& Thorisson, } \\
\text { 1999; Cheung, Chang, \& Scott, 2012; Chodos et al., 2010; Halloran et al., 2003). }\end{array}$ & 1 & 1 & 0 & 2 & 8. \\
\hline \multicolumn{6}{|l|}{ Learning } \\
\hline $\begin{array}{l}\text { Communication in a virtual world not only provides experience of the participant's } \\
\text { own area but also provides experience in a variety of other areas (Chodos et al., 2010; } \\
\text { Raybourn, 2007). }\end{array}$ & 1 & 1 & 1 & 3 & 9. \\
\hline $\begin{array}{l}\text { Development of a training game should focus on communication principles (rather } \\
\text { than domain-specific knowledge). Such development ensures that the training content } \\
\text { is general enough to be applicable to all students (who can switch roles) and still be } \\
\text { meaningful (by seeing role conflicts) and useful (Chodos et al., 2010). }\end{array}$ & 0 & 0 & 1 & 1 & - \\
\hline \multicolumn{6}{|l|}{ Trust } \\
\hline $\begin{array}{l}\text { Trust is higher in a smaller group (e.g. a guild in WoW) and it depends on the } \\
\text { interdependence of members, the persistence of their identity, and the strength of } \\
\text { reputation systems within the group. Voice chat was not related to the trust of others in } \\
\text { the game; it was related to trust in guild members. Self-disclosure was positively related } \\
\text { to trust, but a higher number of public messages sent does not reveal trust to a group } \\
\text { (Ratan, Chung, Shen, Williams, \& Poole, 2010). }\end{array}$ & 1 & 0 & 0 & 1 & - \\
\hline \multicolumn{6}{|l|}{ Problems } \\
\hline $\begin{array}{l}\text { Players reported a number of voice communication problems (e.g. speech not intended } \\
\text { for the listener, background talk, natural or synthetic noise, intentional or unintentional), } \\
\text { which caused lower usability (Gibbs et al., 2004). }\end{array}$ & 1 & 0 & 1 & 2 & 10. \\
\hline $\begin{array}{l}\text { Where a specific domain exists (i.e., a limited domain), a conversational entity can be } \\
\text { represented by a computer (Gustafson, Boye, Fredriksson, Johanneson, \& Königsmann, } \\
\text { 2005). }\end{array}$ & 1 & 0 & 0 & 1 & - \\
\hline $\begin{array}{l}\text { Players reported voice communication problems with synchronicity (e.g. one party out- } \\
\text { of-game for a moment) or identity and privacy issues causing a performance decrease } \\
\text { (Sallnäs, 2002; Wadley et al., 2007). }\end{array}$ & 0 & 1 & 0 & 1 & - \\
\hline
\end{tabular}

In the following subsections, we present the results of this analysis by answering the above questions for each of the ten statements. Furthermore, we provide guidelines for design of a crisis management training virtual environment.

\section{Media Richness Selection}

The first group of statements describes media richness selection and its relation and influence on communication in a virtual environment. Media richness refers to its capacity to process rich information and its ability to provide immediate feedback (Daft \& Lengel, 1986).

\section{Selection of Media is Based on Tasks, Fellows, Organisation, and Prior Experience}

Statement 1: The social richness of the communication medium must be matched with the task characteristics (urgency of the task or cues necessary to perform the task), fellow communicators (number of communicators, their preferences and their required presence) and a person's organisation or users' prior experience with the medium (Sallnäs, 2002; Tan et al., 2012; Wadley et al., 2007).

Selection of a channel as a communication medium that is based on task characteristics has been identified in several cases, where a commander selects a channel based on the importance 
of information, message content, intended call length and to convey essential emotions or to avoid recording.

Selection of media richness based on fellow communicators has been confirmed by several examples including using a leaner medium to address many people, alerting a commander with multiple messages intended for lower level command to ensure delivery, and selecting face-to-face conversation for sensitive information delivery to the next of kin, in addition to selecting a phone to call the emergency centre rather than contacting an on-scene commander because of the estimated availability (busy or free) of the recipient and, finally, by responders selecting a person to talk to, based on his/her level of domain knowledge.

The selection of a channel that is based on organisation guidelines has been confirmed by airport emergency plans, police force guidelines, emergency manuals, commanders and first responders who are reporting. These findings indicate the strong influence of pre-defined methods of communication over other characteristics such as task characteristics or the fellow communicators, named in statement one. The selection of a channel that is based on prior experience has been confirmed by commanders that select a mobile phone over radio because of habit.

Furthermore, the data revealed that statement one could be extended by the channel availability and the type of training instrument that determines the richness of the selected medium. An example of the latter is when the rules of the exercise (e.g. a table-top exercise) prohibit a person from speaking when someone else is talking.

Our conclusion was that statement one was confirmed by the data, and it can be applied when designing a crisis management training environment. Table 4 provides design guidelines derived from this statement, which can be used for the training environment. It describes media from high to low richness and their use in crisis management. Additionally, a leaner medium can be used as a simultaneous channel with a richer medium.

Although the selection of media richness in crisis management should be guided by organisational procedures, the official communication structure can be bypassed for sensitive, technical or longer calls. In addition, the training conditions may allow for higher media richness than real-life.

\section{A Leaner Medium Can Cause Impulsive or Reserved Behaviour but Can be Used for Initial Contact or for Asynchronous Communication}

Statement 2: A leaner medium (e.g. text) can cause impulsive or reserved behaviour, but can be used as a medium for initial contact (e.g. with unknown participants) or for asynchronous

Table 4. Design guidelines on the selection of media richness

\begin{tabular}{|l|l|l|}
\hline \multirow{5}{*}{ Richness } & \multicolumn{1}{|c|}{ Medium } & \multicolumn{1}{c|}{ Purpose } \\
\hline \multirow{4}{*}{ High } & Face to face & Communication at a command centre \\
\cline { 2 - 3 } & & Highly sensitive information \\
\cline { 2 - 3 } & Radio & Negotiation of resources \\
\cline { 2 - 3 } & Radio or phone & Highly important information \\
\cline { 2 - 3 } & & Verification of information received through leaner medium \\
\cline { 2 - 3 } & Phone & Alert high level command \\
\hline \multirow{3}{*}{ Low } & Video link & Monitor a scene \\
\cline { 2 - 3 } & Radio & Monitor a channel \\
\cline { 2 - 3 } & Text & Address a number of people \\
\cline { 2 - 3 } & & Deliver large data sets \\
\hline
\end{tabular}


communication that allows easy information processing (e.g. search in conversation history) (Halloran et al., 2003; Wadley et al., 2007; Wadley et al., 2009).

The use of a leaner medium for asynchronous communication has been confirmed by commanders and first responders using personal and command centre logs, setting up a responder status on a radio device and by high-level commanders who use asynchronous communication for regular updates between command centres with emails or web-based logs. The use of a leaner medium for asynchronous communication and initial contact has been confirmed by observing participants who send text or a pre-recorded voice message during an alert procedure.

The use of a leaner medium for information processing has been confirmed in manuals and by commanders' statements. The manuals state that command centre communication must be recorded and logs can be processed at any time. Commanders and first responders report that communication is recorded for later information reuse. The commanders move from voice to text for communication between command centres because text enables recording and information processing at a suitable time and requires less attention. Moreover, the commanders stated that they take notes in personal logs that are later used for briefing others or answering questions about an incident, and they issue regular updates in the command centres that are used for press releases.

The above analysis has required modification of the statement in several ways. First, the statement should be amended to include the use of leaner medium and asynchronous communication as a back-up channel for voice. Second, the statement should be revised to include the use of verbal communication instead of text under stressful conditions. We have not observed any evidence of impulsive or reserved behaviour when using leaner media and, therefore, a part of the statement is refuted.

To summarise, the statement has been confirmed partially. The difference between crisis management and games lies in the characteristics of crisis management that means that, in crisis management, participants cannot allow themselves to show impulsive or reserved behaviour. Furthermore, the reliability needed in crisis management requires back-up channels, and stressful situations will affect which medium is selected. Table 5 describes the design guidelines for leaner media use.

\section{Four Metaphors for Voice Channels}

Statement 3: Currently, there are four metaphors for designing voice channels in games: broadcasting, landline, mobile phone, and proximity voice chat (Wadley et al., 2005).

The use of a broadcasting channel (i.e. push-to-talk radio) was confirmed by the commanders and first responders, who reported frequent use of different forms of radio (e.g. a personal device, car radio or public address systems) for communication with distant members in crisis management or during training. Moreover, this was confirmed by lower-level commanders on the scene, who reported the use of two radio channels simultaneously to filter information from a lower level before sending it to a higher level command.

Table 5. Design guidelines for leaner media

\begin{tabular}{|c|c|}
\hline Medium Richness & Purpose \\
\hline Leaner media & $\begin{array}{l}\text { Logging of actions and decisions } \\
\text { Transcription of radio communication } \\
\text { Access to operation log for a commander } \\
\text { Back-up channel for voice communication } \\
\text { Communication between command centres } \\
\text { Setting up a responder status }\end{array}$ \\
\hline
\end{tabular}


Face-to-face communication that can be represented by a proximity chat in the virtual environment has been confirmed by commanders and responders' reports about exchanging information face-toface in the command centre and on the scene and further by observations of first responders and lower-level commanders on the scene during a real-life exercise.

The use of mobile phones or landlines has been confirmed by experienced commanders, who acknowledged mobile phone use for inter-agency coordination and by commanders and first responders, who said they used them in the case of a radio system failure, and further by teams of commanders and responders, who said they were not equipped with radio and who used mobiles or landlines as an alternative means of communication or to deliver sensitive messages. Finally, manuals indicated their use in certain phases of the response, e.g. during an alert, but some report that landline phones have been replaced by radio to call national emergency services.

The use of radio broadcasting, mobile phones and landlines has been confirmed by procedures presented by crisis managers (e.g. an alert procedure) and by observations of air traffic controllers and emergency service centre operators who showed regular use of radio and phone.

The statement should be modified to include a simultaneous use of two channels, e.g. two radios, and it should be modified to include channel re-configuration such as a change from broadcasting to mobile phone.

The conclusion from this analysis is that crisis management communication can take full advantage of current metaphors of voice channels in team-based games. The broadcasting channel could carry Push-to-talk radio and Public Address communication, the proximity chat could emulate face-to-face conversations, and the mobile and landline phone channels could be used as an alternative form for information exchange. The design guideline from statement three are described in Table 6. Depending on the context, simultaneous use of multiple channels or an alternative medium (mobile phone as a backup of radio) should be offered.

\section{Groups of People}

The category groups of people define the correlation between the communication channel selection and the organisation of the participants within a group.

\section{Radio for Small Groups}

Statement 4: Voice communication that simulates a radio channel is most useful for a small group of players (6-10) who know each other and are playing a fast-paced game, to coordinate their tactics (issue directions, call for help) and achieve a goal while moving around a geographical area. However, as players reported, the use of multi-channels can cause fragmentation of the party into sub-teams (Raybourn, 2007; Wadley et al., 2007). Proximity chat enables enjoyable game play experiences and user interactions (Carter et al., 2012).

Table 6. Design guidelines for metaphors

\begin{tabular}{|l|l|l|}
\hline Design Metaphor & \multicolumn{1}{|c|}{ Represented By } & \multicolumn{1}{c|}{ Extensions } \\
\hline Broadcasting & $\begin{array}{l}\text { Push-to-talk personal or car radio (portable) } \\
\text { Public address system (fixed location) }\end{array}$ & $\begin{array}{l}\text { Push-to-talk radio should be reconfigurable } \\
\text { and allowed to change between channels }\end{array}$ \\
\hline Mobile & $\begin{array}{l}\text { Personal portable embodiment } \\
\text { Call, text or pre-recorded voice message }\end{array}$ & Backup to broadcasting \\
\hline Landline & Fixed location embodiment & Backup to broadcasting \\
\hline Face to face & Proximity chat & \\
\hline
\end{tabular}


The sharing of a simulated radio channel by a small group that was participating in fast-paced activities and coordinating tactics was confirmed by the observation of five participants in a tabletop exercise. The sharing of a simulated radio channel by a small group to coordinate tactics while moving around an area was confirmed by training managers and commanders. The training managers' presentations offered the use of radio in a fully connected network (everyone talks to everyone) and a tree topology (e.g. one-to-many). The commanders on the scene and in the regional command centre reported being in charge of a group of five to ten people during a real-life crisis or training, which was also confirmed by observation during a large-scale exercise.

The fragmentation of a party into sub-teams by the use of multi-channels has been rejected by manuals, which state that members of a particular group (e.g. Medical or Police) must use a single channel and by the fact that only on-scene commanders were observed to use two radios simultaneously in a large-scale exercise. By doing so, they connect two groups of different command levels.

These statements should be extended to include the possibility of a participant's need to step-out of the communication temporarily. Communication during crisis management can be stressful, and a commander may need to step-out for the purpose of processing information or making a decision. Communication can also exceed the capability of a single person when monitoring multiple channels. In those cases, a representative person is appointed to monitor the communication and to ensure that no information was missed by regularly reporting to the commander. Whether or not knowing each other has an impact on the communication, is analysed in statement seven.

The conclusion from the analysis of statement four is that the use of radio in crisis management highly resembles voice communication, simulating a radio channel in games. Radio is used for coordination of tactics among a small group of responders, who move around an area during a fast-paced action. The main difference observed between games and crisis management was that the inherent organised structure of crisis management mitigated the threat of group fragmentation. However, in cases where a channel becomes overloaded with information, an auxiliary is appointed to listen to the channel. Due to stressful situations in crisis management, it has proven necessary for commanders to step back and take a break from communication. Thus, crisis management has built-in measures to address information overload, whereas games do not. The design guideline from statement four are described in Table 7.

\section{Proximity Chat}

Statement 5: Proximity voice chat, which is a virtual metaphor for face-to-face in the real world, may be necessary where a large number of players would clutter a shared radio channel, players are close to each other in the virtual environment, and the benefit of cues that indicate which direction a sound is travelling from outweighs the inability to speak with distant players (Gibbs et al., 2006).

The use of face-to-face communication by people who are close in the (real) environment and who benefit from cues of sound direction has been confirmed by observations of training and during

Table 7. Design guidelines for small groups

\begin{tabular}{|l|l|l|}
\hline \multicolumn{1}{|c|}{ Metaphor } & \multicolumn{1}{|c|}{ Purpose } & \multicolumn{1}{c|}{ Configurability } \\
\hline Radio & Communication in a small group & Fully connected member or a tree topology \\
\hline & $(5-10$ people $)$ & One or more instances \\
\hline & & Turn off or assign to another person \\
\hline Radio and face-to-face & Information relay by a single person & \\
\hline
\end{tabular}


interviews. The observation showed that small teams of first responders communicated face-to-face frequently during the large-scale exercise. During the interviews, commanders reported frequent use of face-to-face in command centres. When within a close distance of each other on the scene, they preferred face-to-face communication over the use of radio.

The prevention of channel cluttering was refuted by commanders, who stated that the size of a face-to-face group in a command centre is similar to the size of a group that shares a radio channel (5-10 people), and then by commanders in a control room who said they decide on a radio channel configuration that prevents congestion.

In addition to the above confirmation and refusal of the statement, the data indicated that modification is needed. It has to be tailored to regular meetings between commanders and adopted to environmental and technological constraints. Hence, as reported by commanders from different response agencies, the statement should be modified to include the use of face-to-face communication for regular meetings between commanders on the scene. Furthermore, the statement should be modified to include the use of face-to-face communication because of environmental constraints. For example, the use of radio becomes difficult in a noisy environment (machine noise or wind), where the commanders report to meet each other and talk face-to-face instead. Finally, the statement should be modified to include speaking face-to-face as a backup for technology failure or unavailability. For example, when radio fails, the commanders meet face-to-face to exchange information and coordinate response.

Statement five was confirmed, but with the exception of the cluttering of a shared radio channel, which is avoided in crisis management by certain communication configurations. Also, instead of filtering out the number of people on the channel, in crisis management, face-to-face communication is used when talking to people within reach. The benefits of face-to-face communication are enjoyed by first responders and commanders, and face-to-face communication is preferred over radio. Again, in this statement, we see the differences in the two areas emerging in the inherent structures of crisis management. Furthermore, the required reliability of crisis management and the difficult working surroundings, which are affected by synthetic or natural noise due to extreme weather, distinguishes crisis management from games. The design guidelines implied from statement five are described in Table 8.

\section{Identity of People}

The identity of people group focuses on identity management and addressing people during communication in a virtual environment.

\section{Addressing People and Channel Control}

Statement 6: Players engaged in a virtual environment had difficulty identifying who was speaking, determining who could hear what they said and knowing whether it was heard at all. Players reported that the voice channel had inadequate facilities to control what was heard and what was sent and that it introduced delay. As a result, it can inhibit a convivial computer-mediated social

Table 8. Design guidelines for proximity chat

\begin{tabular}{|c|l|l|}
\hline Metaphor & \multicolumn{1}{|c|}{ Purpose } & \multicolumn{1}{c|}{ Trigger of Proximity Chat } \\
\hline Face-to-face & $\begin{array}{l}\text { Small group of 5-10 people } \\
\text { who work on the same task } \\
\text { and are close }\end{array}$ & $\begin{array}{l}\text { Characters get close in virtual environment } \\
\text { Regular time intervals } \\
\text { Noise can make radio communication difficult and hence a face-to- } \\
\text { face meeting is required. } \\
\text { As a backup when there is technology failure, e.g. radio fails. }\end{array}$ \\
\hline
\end{tabular}


interaction (Gibbs et al., 2004; Gibbs et al., 2006; Wadley et al., 2009). Voice reveals identity better than text which makes it more sociable but can interfere role-play and pseudonymity (Wadley et al., 2015).

The problem of identifying who was speaking has been refuted in crisis management by three indicators. The commanders and training managers and crisis management procedures reported the use of call signs. Then commanders stated that they know each other and those (at a certain level) who knew each other were able to recognise each other's voices. Finally, the use of one-to-one communications such as landlines, mobile phones, radio between two persons/command centres and radio display help with the identification of a speaker.

However, the problem of identifying who was speaking has been recognised when the participants occasionally forgot to use call signs. One of the causes was a lack of training. Another one was that participants started to introduce themselves too early, and the first two seconds of the radio speech are not transmitted.

The uncertainty that a message has been received was refuted by the following statements. First, response agencies confirmed reception of an alert message and, when unsure, they called back. Then, personnel at the command level regularly confirmed the message reception and the personnel called by a call sign replied using the call sign of the origin. Finally, during the real exercise a commander on the scene could perform a visual check to see whether a task had been performed as requested and during a table-top exercise visual cues (e.g. nodding) were sent out in simulated radio communication. Uncertainty about message delivery was supported by first responders on the scene, who did not confirm the reception of a message.

The problem of identifying a message recipient has been refuted by speaking to a specific person using a call sign or addressing all of the receivers who use or monitor the channel. The problem of controlling the communication channel has been refuted by the use of appropriate devices (discussed in statement three), the use of push-to-talk radio, where speaking occurs only when a button is pressed and speaking on a selected channel only. Finally, the problem is refuted by commanders, who have stated that problems with channel control depend on a person's individual skills, his or her age and previous skills.

Certainly, as described by statement six, there is a difference between games and crisis management with respect to voice communication. Although there was some contradictory evidence, we concluded that problems with the identification of who is speaking or addressed, whether the message is delivered or how to control the channel, have been mostly refuted. Additionally, the findings on communications in crisis management did not reveal any inhibited interactions or any indication of delay caused by inadequate control. Thus, we can conclude that this statement does not apply to crisis management. Again, the reason is the difference in the inherent communication protocol of crisis management. From the analysis of this statement, we suggest further design guidelines as presented in Table 9.

Table 9. Design guidelines for addressing people and controlling channel

\begin{tabular}{|l|l|}
\hline \multicolumn{1}{|c|}{ Metaphor } & \multicolumn{1}{c|}{ Type of Control } \\
\hline One-to-one (mobile, landline, face-to-face) & $\begin{array}{l}\text { Select recipient } \\
\text { Indicate source of communication }\end{array}$ \\
\hline Broadcasting & $\begin{array}{l}\text { Use of call signs } \\
\text { Push-to-talk functionality } \\
\text { Should allow recipient to contact the source } \\
\text { Voice recognition not considered relevant }\end{array}$ \\
\hline All voice metaphors & Avatars should be anonymized for voice \\
\hline
\end{tabular}




\section{A Player's Identity Affects Learning and Coordination}

Statement 7: Not knowing who is talking in a distributed player setting can have a negative effect on learning and coordination in team-based war games (more/longer utterances to find out who is present, what is their level of skills or to address the person). On the other hand, knowing a partner results in fair decision making (Halloran, 2009; Halloran et al., 2004; Yamamori et al., 2008).

We could not validate the effect of unknown identity on learning and coordination because, as stated in statement six, first responders and commanders know whom they are talking to. However, we can say that, in a single interview, a crisis commander confirmed good coordination between response agencies in which commanders know each other. This is in accordance with (Wadley et al., 2015) who states that identifying someone by voice makes the communication more social. An implication for design from this statement is that, for training purposes, avatars should be anonymised (see Table 7). All of the players will then have the opportunity to follow the training procedures and practice role-play without someone having the advantage of knowing others.

\section{Avatar Behaviour}

Because players in a virtual environment are represented by avatars, the group avatar behaviour queries the visual appearance of the virtual character and the embodiment of non-verbal communication functions.

\section{Coupling of Players' Verbal and Visual Actions}

Statement 8: Where visual representation is available (e.g. videoconference, collaborative virtual environment), verbal actions should be coupled with postural, gestural and proximity information of the player embodiment. This information can help identify the speaker and can increase communication during participants' performances (Cassell \& Thorisson, 1999; Chodos et al., 2010; Halloran et al., 2003)

The coupling of verbal and visual representation has been confirmed by several cases where commanders' actions were visibly coupled with verbal description during a table-top exercise and by a commander pointing to a location on the scene while tasking first responders during a real-life exercise. Because we conclude that statement eight has been validated in crisis management, we can recommend that proximity chat in a virtual environment should allow gestures.

\section{Learning}

The learning group focuses on the training aspects that communication provides in a virtual environment.

\section{Experience Sharing}

Statement 9: Communication in a virtual world not only provides experience of the participant's own area but also provides experience in a variety of other areas (Chodos et al., 2010; Raybourn, 2007).

Provision of experience from other roles has been confirmed by observations of real-life exercises and by interviews on crisis management training.

They indicated that the coordinators learn about the other teams' tasks while monitoring a shared communication channel, Police learn about Fire fighters' needs while making a secure area for them, Police teams learn about each other's methods while negotiating security responsibilities, 
and Police learn about the medical domain while organising casualty transport with a medical team. Then the responders, who change roles during incident response, also learn skills in the new field (e.g. fire fighters as medics).

Although, as one commander said, a person learns through the scenario itself, he or she mainly learns from the discussions that take place in the training room and in the plenary meetings. Furthermore, commanders prefer to get to know each other well and to learn their roles in a large-scale exercise and one commander pointed out that training can fight off rivalry between coordinating teams.

Thus, a number of examples have validated this statement. We concluded that experience sharing is important in crisis management and that there are ample opportunities for learning from each other, about procedures, situations and roles. The reason that experience sharing is particularly important is that, especially in smaller locations, human resources are scarce, making it important for a person to perform the tasks required in different roles. For example, a fire fighter who participates in a rescue by fighting fire may later be triaging patients or driving an ambulance. We did not see the need to propose a design guideline from this statement. Communication, as we have described it until now, facilitates experience sharing.

\section{Problems}

The final group, the problem group, contains statements that point to technical or contextual problems.

\section{Problems of Voice Communication}

Statement 10: Players reported a number of voice communication problems (e.g. speech not intended for the listener, background talk, natural or synthetic noise, intentional or unintentional) which caused lower usability (Gibbs et al., 2004).

The communication hindrances such as environmental noise or unrelated conversation were confirmed by all of the participants including training managers on the scene or in a command centre during a large-scale exercise, and confirmed as well by commanders who had reported experiencing problems with environmental noise, which is louder on the scene and lower in the command centre. One commander reported special communication training, teaching how to deliver a clear message.

Because several additional types of problems were observed in crisis management, a few amendments to statement ten were required. Some of the issues have been mentioned in previous sections but appear here again. Examples are technical constraints and the context of the crisis. Other examples are new but draw their characteristics from the nature of the crisis management, e.g. the need for concise expression and the need for high reliability. Yet others result from the heterogeneous background of the large number of participants and require accessibility of the technology to all regardless of their background and abilities. First, the statement should be modified to include the problems that are related to the use of the channel, such as unanswered calls, unsatisfied requests for information or selection of an incorrect communication channel. Second, the statement should be extended to include the use of multiple channels simultaneously (e.g. using two radios). Third, the statement may be modified to include channel liability due to technical or contextual problems (e.g. a handheld radio on the scene is subject to environmental noises, or certain technology may be liable to breakdown). Fourth, the statement may be modified to include communications problems that are related to a person such as individual communication skills, previous experience with computers, inadequate communication skills of the participants or their respect for the communications plan. Fifth, the statement should be modified to include problems with respect to the delivery of irrelevant information. Sixth, the statement may be changed to include communications problems resulting from competition, such as fighting over the scene primacy.

We concluded that this statement has been validated with the data analysed, albeit with several additions. All of the participants in our study confirmed that environmental noise was a major problem 
in communication. Other problems, such as background talk or speech that is not intended for the listener, were also confirmed. Some of these problems resulted from an incorrect communication setup. However, no music or intentional disturbances of the channel have been reported. Finally, as elicited above, several additional communication problems have been observed or reported during interviews. The design guidelines derived from statement ten are described in Table 10.

\section{Summary of Results}

The summary of results is provided in Table 11. It organises the statements by group. For each statement, there is a brief summary and a conclusion on its support or refusal in crisis management. If applicable, each statement has additions that were deemed necessary while transferring the statement from online games to crisis management training in a virtual environment. Two out of the ten statements were refuted in crisis management, five were confirmed and three were partly confirmed. In six of the eight sentences that were confirmed or partly confirmed, additions had to be made for crisis management.

\section{CONCLUSION}

\section{Outcome of the Research Study}

At the onset of this research study, we aimed to answer the question of whether and to what extent crisis management training in a virtual environment could take advantage of voice communication in online multiplayer games. Given the results summarised in the previous section we conclude that virtual environments for crisis management training can take advantage of communication in online multiplayer games. From a practical standpoint, we have suggested design guidelines to be used in the design of a virtual environment for crisis management training. Theoretical implications will be discussed later in this section.

While a majority of the statements, which were derived from on-line games, could be confirmed and thus adopted in crisis management training, others had no match in the crisis management domain. These results accorded with our expectations at the onset of the validation part of the study. However, what we could not have predicted was which statements from the broader online games are transferrable to crisis management training. For example, statement one, which links media richness selection with communication characteristics, has been fully confirmed, while statement six, which discusses the identity problems of players, has been refuted. Especially noticeable is the need for addressing environmental and situated noise in crisis management. According to participants in the study, this is a paramount feature of a virtual environment because it can have a great impact on work performance.

The characteristics of crisis management are especially influential and apparent in the results. What is most obvious is that such an operation follows organisational guides (e.g. statement one, selection of the medium according to the guidelines), is formal (e.g. statement two, no impulsive or reserved behaviour, and statement six, identifying who is speaking), is characterised by a complexity in

Table 10. Design guidelines for problems in communication

\begin{tabular}{|l|l|}
\hline \multicolumn{1}{|c|}{ Metaphor Extension } & \multicolumn{1}{c|}{ Solution to a Problem } \\
\hline Alternative to the primary metaphor & $\begin{array}{l}\text { Reach a person who does not reply or is not reachable. } \\
\text { Training to avoid bad habits (e.g. talk face-to-face instead of keeping all } \\
\text { informed by radio, use of mobile phone when not recommended) }\end{array}$ \\
\hline Noise & $\begin{array}{l}\text { Realistic training conditions represented by environment and technology- } \\
\text { induced noises. The noise should depend on a trainee's action (e.g. distance } \\
\text { from the noise-emitting object). }\end{array}$ \\
\hline
\end{tabular}


Table 11. Summary of statements, their validation and extensions for crisis management

\begin{tabular}{|c|c|c|c|c|}
\hline \multicolumn{2}{|c|}{ Statement } & \multirow{2}{*}{ Statement of Online Games } & \multirow{2}{*}{$\begin{array}{l}\text { Confirmed in } \\
\text { Crisis } \\
\text { Management }\end{array}$} & \multirow{2}{*}{$\begin{array}{l}\text { Additions for Crisis } \\
\text { Management }\end{array}$} \\
\hline Group & No. & & & \\
\hline \multirow{3}{*}{$\begin{array}{l}\text { Media } \\
\text { richness } \\
\text { selection }\end{array}$} & 1 & $\begin{array}{l}\text { Selection of media based on tasks, } \\
\text { fellows, organisation and prior } \\
\text { experience }\end{array}$ & Yes & $\begin{array}{l}\text { Medium availability and type of } \\
\text { training instrument used }\end{array}$ \\
\hline & 2 & $\begin{array}{l}\text { Leaner media (e.g. text) can cause } \\
\text { impulsive or reserved behaviour but } \\
\text { can be used for initial contact or for } \\
\text { asynchronous communication }\end{array}$ & $\begin{array}{l}\text { Partially, but not } \\
\text { for impulsive or } \\
\text { reserved behaviour }\end{array}$ & $\begin{array}{l}\text { Media with higher richness } \\
\text { should be used under stressful } \\
\text { conditions, and to achieve higher } \\
\text { reliability lower medium should } \\
\text { be used as a backup channel. }\end{array}$ \\
\hline & 3 & $\begin{array}{l}\text { Four metaphors for voice channels: } \\
\text { broadcasting, landline, mobile phone } \\
\text { and proximity chat }\end{array}$ & Yes & $\begin{array}{l}\text { Multiple, simultaneous channels } \\
\text { and reconfigurable channels or } \\
\text { media depending on context. }\end{array}$ \\
\hline \multirow[t]{2}{*}{$\begin{array}{l}\text { Groups of } \\
\text { people }\end{array}$} & 4 & $\begin{array}{l}\text { Radio channel is most useful for a } \\
\text { small group of players who know } \\
\text { each other but multi-channels can } \\
\text { cause fragmentation }\end{array}$ & $\begin{array}{l}\text { Partially, but } \\
\text { fragmentation is } \\
\text { prevented }\end{array}$ & $\begin{array}{l}\text { Possibilities to step out of the } \\
\text { conversation and to monitor } \\
\text { multiple channels simultaneously. }\end{array}$ \\
\hline & 5 & $\begin{array}{l}\text { Proximity chat is useful where } \\
\text { a large number of players would } \\
\text { clutter a shared radio channel and } \\
\text { players are close to each other in the } \\
\text { virtual environment. }\end{array}$ & $\begin{array}{l}\text { Partially, but } \\
\text { cluttering is not } \\
\text { identified }\end{array}$ & $\begin{array}{l}\text { Face-to-face is used for regular } \\
\text { meetings and when there are } \\
\text { environmental or technology } \\
\text { constraints. }\end{array}$ \\
\hline \multirow[t]{2}{*}{$\begin{array}{l}\text { Identity of } \\
\text { people }\end{array}$} & 6 & $\begin{array}{l}\text { Players had difficulty identifying } \\
\text { who was speaking. Difficult to } \\
\text { control what was heard and what } \\
\text { was sent. }\end{array}$ & No & \\
\hline & 7 & $\begin{array}{l}\text { A player's identity can negatively } \\
\text { affect learning and coordination }\end{array}$ & No & \\
\hline $\begin{array}{l}\text { Avatar } \\
\text { behaviour }\end{array}$ & 8 & $\begin{array}{l}\text { Where visual representation is } \\
\text { available, verbal actions should be } \\
\text { coupled with postural, gestural and } \\
\text { proximity information of the player } \\
\text { embodiment. }\end{array}$ & Yes & \\
\hline Learning & 9 & Experience sharing & Yes & \\
\hline Problems & 10 & $\begin{array}{l}\text { Problems of voice communication, } \\
\text { e.g. background talk, natural or } \\
\text { synthetic noise, intentional or } \\
\text { unintentional }\end{array}$ & Yes & $\begin{array}{l}\text { Unnecessary information } \\
\text { delivery, problems resulting from } \\
\text { competition such as fighting } \\
\text { over the scene primacy and skill } \\
\text { dependence. }\end{array}$ \\
\hline
\end{tabular}

the topology of the communication (e.g. statement three, using two or more channels simultaneously), produces reliable data and the decision making is highly critical (e.g. statement four on the logging of information or pausing to enable decision making). The operation shows impact of a noisy environment on task performance (statements five and ten), has identification of speaker or recipient by call signs or by channel selection (statement six) and allows members to share each other's experiences by communication or coordination (statement nine). While these characteristics are not entirely unique for crisis management, we expect that they are not generic for all domains.

Other statements, which have been confirmed in crisis management training, are likely to be usable in other similar domains, e.g. training in the military domain or individual response agencies. 
A few examples are the selection of media based on fellows, tasks and organisation; the asynchrony of information; metaphors, gestures and postures increasing the meaning of the communication, and the proximity of the conversation being dependent on the size of the group.

The design guidelines that were identified for each statement can be useful for crisis management training environments and, depending on their generality, for other virtual environments. Some of the design guidelines are especially useful for training because they can be variable from one training level to the next. For example, a trainee can train first without environmental noise and then, as difficulty levels increase, with it. Thus, he or she would receive, gradually, an increasingly more difficult training environment. This scenario is in accordance with the Variable Uncertainty Framework which has been proposed for designing scenarios for training environments and includes three variable dimensions, the number of events, the randomness of events, and the situational complexity around events (Field, Rankin, Pal, Eriksson, \& Wong, 2011).

Despite the positive results of this research study, it leaves open several avenues for further study. First, a more in-depth research analysis of a communication protocol could provide further information on impulsive or reserved behaviour (second statement) or a delay of the message delivered (statement six). Second, future research should include an evaluation of the design guidelines. The evaluation of their validity for a virtual environment for learning is necessary in any prototype of a training system. Previous review of validation of simulators has illustrated that the area has few accepted definitions and measurement methods, making it a challenging area (Schout, Hendrikx, Scheele, Bemelmans, \& Scherpbier, 2010). Schout et al. (2010) have proposed that a prerequisite for validating a simulator researchers should conduct a training needs analysis to evaluate the existing requirements for training and to look at program requirements in a training program design. Third, it could be worthwhile to evaluate, in practice, how the variable factors characterised in the statements can be used for designing training scenarios. Fourth, the findings on communication were collected from the related domains of online multiplayer games and collaborative virtual environments. These findings provide information about textual and voice communication. This work should be extended to include other forms of communication in the virtual environment (e.g. videoconferencing) and their applicability for crisis management training.

\section{Relation to Theories}

This section describes several theories that can be related to the results and that can afford grounds for further research. The results describe voice communication in the crisis management domain as a safety-critical process that must provide reliable information delivery to an appropriate destination. Problems of communications have been identified and they can have implications for collective decision-making and coordination of action. Categorically, the problems were, first, technological, such as communications failure and simultaneous use of multiple devices; second, sociological, including the lack of a common vocabulary, the habitual use of channels, the overwhelming nature of the tasks and the stressful environment; and third, organisational, because of different hierarchical structures in communication. In addition to these three categories identified by Manoj and Baker (2007) and confirmed by this study, the results suggest that the physical environment or the context is a prominent characteristic that has an effect on communication.

Another theory or a model to which this research can relate is Berlo's (1960) communication model, which describes the nature of the receiver, the sender, the message and the channel. The communication between the source and receiver is mediated by messages sent over a channel. A source is a person with the intention of transmitting a message that represents his/her thoughts. It is influenced by communication skills (e.g. ability to speak, write), attitude towards the audience, subject of communication and oneself, knowledge of the subject and the social system and culture (e.g. beliefs, religion). The message component represents the information as expressed by the source, which consists of the content, elements, treatment, structure and code. The content is the entire information of a message assembled from elements such as words or gestures, into a structure (e.g. 
a sentence). The selected treatment can include formal or natural communication. Code refers to the language that is used or other rules and conventions governing verbal and gestural communication. The channel is the medium by which the message is encoded and decoded, as represented by five senses. A receiver is a person at the destination of the communication chain trying to understand the message using their own communication skills, knowledge and social system. Statements one, two, four, six and seven relate to the social systems of the source or the receiver. Statement eight relates to the message, specifically the channel (e.g. visual or verbal) and code (e.g. gestures). Finally, statement nine relates to knowledge of the subject.

Whereas communication can be viewed as the medium of content, it is not concerned with the behaviour of the trainee. It is worth considering how the communication relates to a theory of engagement, which describes how well a player (a trainee) is pulled into the game. Engagement has been characterised by Benyon (2010, p. 95) as including identity as a sense of authenticity for the expression of self, adaption relating to change and personalisation along with changing levels of difficulty, and the narrative concerns of telling a good story, immersion in the sense of feeling wholly involved, and flow, defined as the gradual flow of one state to the next. Based on 12 in-depth interviews and on existing theories in gaming, Whitton (2011) has constructed a model of engagement in which learning consists of five factors, i.e. challenge, control, immersion, interest in the activity, and purpose. Applying Whitton's theory (2011) to our results we take a few examples. Noise will increase immersion, and a selection of communication devices, i.e. face-to-face. Radio or mobile phones provide different avenues of communication and thus control. On the other hand, noise can provide a challenge for the trainee and can introduce uncertainty in completing a task, which can also be increased by a complex topology of communication, such as multiple simultaneous channels. The last two factors, interest in the activity and purpose, could not be found in the ten statements.

This paper contributes to the transferability of knowledge between domains. It adds to previous work, which has proposed ways of designing user interfaces by adaptation from other domains, such as games (Shepherd \& Bleasdale-Shepherd, 2011). Thus, it contributes to answering the question to what extent technology can be transferred between application domains (Harris \& Harris, 2004). 


\section{REFERENCES}

Adelman, L., Christian, M., Gualtieri, J., \& Bresnick, T. A. (1998). Examining the effects of communication training and team composition on the decision making of Patriot air defense teams. IEEE Transactions on Systems, Man, and Cybernetics. Part A, Systems and Humans, 28(6), 729-741. doi:10.1109/3468.725346

Bartle, R. A. (2003). Not Yet you Fools! games+girls=advance. Retrieved from http://www.gamegirladvance. com/archives/2003/07/28/not_yet_you_fools.html\#000424

Bayerl, P. S., \& Lauche, K. (2010). Technology Effects in Distributed Team Coordination High-Interdependency Tasks in Offshore Oil Production. Computer Supported Cooperative Work, 19(2), 139-173. doi:10.1007/ s10606-010-9107-x

Benyon, D. (2010). Designing interactive systems: a comprehensive guide to HCI and interaction design. Pearson Education.

Berlo, D. K. (Ed.). (1960). The process of communication. New York, New York: Holt, Rinehart, \& Winston.

Bharosa, N., Lee, J., \& Janssen, M. (2010). Challenges and obstacles in sharing and coordinating information during multi-agency disaster response: Propositions from field exercises. Information Systems Frontiers, 12(1), 49-65. doi:10.1007/s10796-009-9174-z

Boyle, E. A., Hainey, T., Connolly, T. M., Gray, G., Earp, J., Ott, M., \& Pereira, J. et al. (2016). An update to the systematic literature review of empirical evidence of the impacts and outcomes of computer games and serious games. Computers \& Education, 94, 178-192. doi:10.1016/j.compedu.2015.11.003

Brehmer, B., \& Dörner, D. (1993). Experiments with computer-simulated microworlds: Escaping both the narrow straits of the laboratory and the deep blue sea of the field study. Computers in Human Behavior, 9(2-3), 171-184. doi:10.1016/0747-5632(93)90005-D

Carter, M., Wadley, G., \& Gibbs, M. (2012). Friendly, don't shoot!: how communication design can enable novel social interactions. Paper presented at the 24th Australian Computer-Human Interaction Conference. doi: $10.1145 / 2414536.2414548$

Cassell, J., \& Thorisson, K. R. (1999). The power of a nod and a glance: Envelope vs. emotional feedback in animated conversational agents. Applied Artificial Intelligence: An International Journal, 13(4), 519-538. doi:10.1080/088395199117360

Cheung, V., Chang, Y.-L. B., \& Scott, S. D. (2012). Communication channels and awareness cues in collocated collaborative time-critical gaming. Paper presented at the ACM 2012 conference on Computer Supported Cooperative Work, Seattle, Washington, USA. doi:10.1145/2145204.2145291

Chodos, D., Stroulia, E., Boechler, P., King, S., Kuras, P., Carbonaro, M., \& Jong, E. d. (2010). Healthcare education with virtual-world simulations. Paper presented at the 2010 ICSE Workshop on Software Engineering in Health Care, Cape Town, South Africa. doi:10.1145/1809085.1809097

Clark, H., \& Brennan, S. A. (1991). Grounding in communication. In L. B. Resnick, J. M. Levine, \& S. D. Teasley (Eds.), Perspectives on socially shared cognition. doi:10.1037/10096-006

Cooke, N. J., Gorman, J. C., Myers, C. W., \& Duran, J. L. (2013). Interactive Team Cognition. Cognitive Science, 37(2), 255-285. doi:10.1111/cogs.12009 PMID:23167661

Creutzfeldt, J., Hedman, L., Medin, C., Heinrichs, W. L., \& Felländer-Tsai, L. (2010). Exploring virtual worlds for scenario-based repeated team training of cardiopulmonary resuscitation in medical students. Journal of Medical Internet Research, 12(3), e38. doi:10.2196/jmir.1426 PMID:20813717

Crookall, D. (2010). Serious Games, Debriefing, and Simulation/Gaming as a Discipline. Simulation \& Gaming, 41(6), 898-920. doi:10.1177/1046878110390784

Daft, R. L., \& Lengel, R. H. (1986). Organizational information requirements, media richness and structural design. Journal Management Science, 32(5). 
Deterding, S., Dixon, D., Khaled, R., \& Nacke, L. (2011). From game design elements to gamefulness: defining "gamification". Paper presented at the 15th International Academic MindTrek Conference: Envisioning Future Media Environments, Tampere, Finland. doi:10.1145/2181037.2181040

Endsley, M. R., \& Jones, W. (2013). Situation awareness. The Oxford Handbook of Cognitive Engineering, 88.

Field, J., Rankin, A., Pal, J. d., Eriksson, H., \& Wong, W. (2011). Variable Uncertainty: Scenario Design for Training Adaptive and Flexible Skills. Paper presented at the European Conference on Cognitive Ergonomics. doi:10.1145/2074712.2074719

Gibbs, M., Hew, K., \& Wadley, G. (2004). Social Translucence of the Xbox Live Voice Channel. In M. Rauterberg (Ed.), Entertainment Computing - ICEC 2004, LNCS (Vol. 3166, pp. 407-499): Springer Berlin / Heidelberg. doi:10.1007/978-3-540-28643-1_48

Gibbs, M., Wadley, G., \& Benda, P. (2006). Proximity-based chat in a first person shooter: using a novel voice communication system for online play. Paper presented at the $3 \mathrm{rd}$ Australasian conference on Interactive entertainment, Perth, Australia.

Grantcharov, T. P., Kristiansen, V. B., Bendix, J., Bardram, L., Rosenberg, J., \& Funch-Jensen, P. (2004). Randomized clinical trial of virtual reality simulation for laparoscopic skills training. British Journal of Surgery, 91(2), 146-150. doi:10.1002/bjs.4407 PMID:14760660

Greef, T. d., \& Arciszewski, H. (2007). A closed-loop adaptive system for command and control. Paper presented at the 3rd international conference on Foundations of augmented cognition, Beijing, China. doi:10.1007/9783-540-73216-7_31

Gustafson, J., Boye, J., Fredriksson, M., Johanneson, L., \& Königsmann, J. (2005). Providing computer game characters with conversational abilities. In Intelligent Virtual Agents IVA 2005, LNCS (Vol. 3661, pp. 37-51). Springer-Verlag. doi:10.1007/11550617_4

Haferkamp, N., Kraemer, N. C., Linehan, C., \& Schembri, M. (2011). Training disaster communication by means of serious games in virtual environments. Entertainment Computing, 2(2), 81-88. doi:10.1016/j. entcom.2010.12.009

Halloran, J. (2009). It's Talk, But Not as We Know It: Using VoIP to Communicate in War Games. Paper presented at the 2009 Conference in Games and Virtual Worlds for Serious Applications. doi:10.1109/VS-GAMES.2009.36

Halloran, J., Fitzpatrick, G., Rogers, Y., \& Marshall, P. (2004). Does it matter if you don't know who's talking?: multiplayer gaming with voiceover IP. Paper presented at the CHI '04 extended abstracts on Human factors in computing systems, Vienna, Austria. doi:10.1145/985921.986027

Halloran, J., Rogers, Y., \& Fitzpatrick, G. (2003). From text to talk: Multiplayer games and voiceover IP. Paper presented at the 2003 Digital Games Research Association Conference, Utrecht.

Harris, D., \& Harris, F. J. (2004). Evaluating the transfer of technology between application domains: A critical evaluation of the human component in the system. Technology in Society, 26(4), 551-565. doi:10.1016/S0160$791 \mathrm{X}(04) 00055-7$

Heinrichs, W. L., Youngblood, P., Harter, P. M., \& Dev, P. (2008). Simulation for team training and assessment: Case studies of online training with virtual worlds. World Journal of Surgery, 32(2), 161-170. doi:10.1007/ s00268-007-9354-2 PMID:18188640

Jain, S., \& McLean, C. R. (2005). Integrated simulation and gaming architecture for incident management training. Paper presented at the 37th conference on Winter simulation, Orlando, Florida. doi:10.1109/WSC.2005.1574338

Johnston, H., \& Whitehead, A. (2009). Distinguishing games, serious games, and training simulators on the basis of intent. Paper presented at the Proceedings of the 2009 Conference on Future Play on @ GDC Canada, Vancouver, British Columbia, Canada. doi:10.1145/1639601.1639607

Jones, D. G., \& Endsley, M. R. (1996, June). Sources of situation awareness errors in aviation. Aviation, Space, and Environmental Medicine, 67(6), 507-512. PMID:8827130

Klein, G. (1993). A recognition-primed decision (RPD) model of rapid decision making. In G. Klein, J. Orasanu, R. Calderwood, \& C. Zsambok (Eds.), Decision making in action: Models and methods. Westport, CT, US: Ablex Publishing. 
Li, S.-C. S. (2007). Computer-mediated communication and group decision making. Small Group Research, 38(5), 593-614. doi:10.1177/1046496407304335

Manoj, B. S., \& Baker, A. H. (2007). Communication challenges in emergency response. Communications of the ACM, 5O(3), 51-53. doi:10.1145/1226736.1226765

Potkonjak, V., Gardner, M., Callaghan, V., Mattila, P., Guetl, C., Petrović, V. M., \& Jovanović, K. (2016). Virtual laboratories for education in science, technology, and engineering: A review. Computers \& Education, 95, 309-327. doi:10.1016/j.compedu.2016.02.002

Ratan, R. A., Chung, J. E., Shen, C., Williams, D., \& Poole, M. S. (2010). Schmoozing and Smiting: Trust, Social Institutions, and Communication Patterns in an MMOG. Journal of Computer-Mediated Communication, 16(1), 93-114. doi:10.1111/j.1083-6101.2010.01534.x

Raybourn, E. M. (2007). Applying simulation experience design methods to creating serious game-based adaptive training systems. Interacting with Computers, 19(2), 206-214. doi:10.1016/j.intcom.2006.08.001

Salas, E., Cooke, N. J., \& Rosen, M. A. (2008). On Teams, Teamwork, and Team Performance: Discoveries and Developments. Human Factors: The Journal of the Human Factors and Ergonomics Society, 50(3), 540-547. doi:10.1518/001872008X288457 PMID:18689065

Salas, E., DiazGranados, D., Klein, C., Burke, C. S., Stagl, K. C., Goodwin, G. F., \& Halpin, S. M. (2008). Does Team Training Improve Team Performance? A Meta-Analysis. Human Factors: The Journal of the Human Factors and Ergonomics Society, 50(6), 903-933. doi:10.1518/001872008X375009 PMID:19292013

Sallnäs, E.-L. (2002). Collaboration in multi-modal virtual worlds: Comparing touch, text, voice and video. In The social life of avatars (pp. 172-187). New York: Springer.

Schout, B. M. A., Hendrikx, A. J. M., Scheele, F., Bemelmans, B. L. H., \& Scherpbier, A. J. J. A. (2010). Validation and implementation of surgical simulators: A critical review of present, past, and future. Surgical Endoscopy, 24(3), 536-546. doi:10.1007/s00464-009-0634-9 PMID:19633886

Shepherd, I., \& Bleasdale-Shepherd, I. (2011). The design-by-adaptation approach to universal access: Learning from videogame technology. Universal Access in the Information Society, 10(3), 319-336. doi:10.1007/s10209010-0204-x

Tan, W.-K., Tan, C.-H., \& Teo, H.-H. (2012). Conveying information effectively in a virtual world: Insights from synthesized task closure and media richness. Journal of the American Society for Information Science and Technology, 63(6), 1198-1212. doi:10.1002/asi.22600

Toups, Z. O., Kerne, A., \& Hamilton, W. A. (2011). The Team Coordination Game: Zero-fidelity simulation abstracted from fire emergency response practice. ACM Transactions on Computer-Human Interaction, 18(4), 23. doi: $10.1145 / 2063231.2063237$

Wadley, G. (2011). Voice in virtual worlds. (Ph.D.). The University of Melbourne.

Wadley, G., Carter, M., \& Gibbs, M. (2015). Voice in Virtual Worlds: The Design, Use, and Influence of Voice Chat in Online Play. Human-Computer Interaction, 30(3-4), 336-365. doi:10.1080/07370024.2014.987346

Wadley, G., Gibbs, M., \& Benda, P. (2005). Towards a framework for designing speech-based player interaction in multiplayer online games. Paper presented at the Proceedings of the second Australasian conference on Interactive entertainment, Sydney, Australia.

Wadley, G., Gibbs, M., \& Benda, P. (2007). Speaking in character: Using voice-over-IP to communicate within MMORPGs. Paper presented at the Proceedings of the 4th Australasian conference on Interactive entertainment, Melbourne, Australia.

Wadley, G., Gibbs, M., \& Ducheneaut, N. (2009). You can be too rich: Mediated communication in a virtual world. Paper presented at the 21st Annual Conference of the Australian Computer-Human Interaction Special Interest Group: Design: Open 24/7, Melbourne, Australia.

Whitton, N. (2011). Game Engagement Theory and Adult Learning. Simulation \& Gaming, 42(4). 
Wiecha, J., Heyden, R., Sternthal, E., \& Merialdi, M. (2010). Learning in a virtual world: Experience with using second life for medical education. Journal of Medical Internet Research, 12(1), e1. doi:10.2196/jmir.1337 PMID:20097652

Yamamori, T., Kato, K., Kawagoe, T., \& Matsui, A. (2008). Voice matters in a dictator game. Experimental Economics, 11(4), 336-343. doi:10.1007/s10683-007-9168-y

Zarraonandia, T., Vargas, M., Díaz, P., \& Aedo, I. (2009). A virtual environment for learning airport emergency management protocols. In J. Jacko (Ed.), Human-Computer Interaction. Ambient, Ubiquitous and Intelligent Interaction (Vol. 5612, pp. 228-235). Springer Berlin Heidelberg. doi:10.1007/978-3-642-02580-8_25

Zyda, M. (2005). From Visual Simulation to Virtual Reality to Games. Computer, 38(9), 25-32. doi:10.1109/ MC.2005.297

Jan Rudinsky is senior user experience researcher at ExperienceU, member of a global UXalliance, helping commercial and nonprofit organizations develop highly usable and desirable software. Before joining ExperienceU Jan was postdoctoral researcher in the UK and lceland engaged in EU-FP7 research projects oriented at training and education of emergency services and science students. The research results contributed to the projects development and were presented and demonstrated at the international conferences and delivered in the form of high quality documents to European Commission. Jan has received doctoral degree in information technology from the Czech Technical University in Prague in 2010. Jan's research interests include user experience, communications and networking.

Ebba Thora Hvannberg is a professor of Computer Science, School of Engineering and Natural Sciences, University of Iceland. Dr. Hvannberg has a B.S. in computer science from University of Iceland, and an M.S. and a Ph.D. from Rensselaer Polytechnic Institute, New York. Her research areas include human computer interaction and software engineering. She has participated in several international projects on advanced multimedia services to residential users, software process improvement, technology enhanced learning, air traffic control, usability evaluations, and software for crisis management. The most recent projects are the COST sponsored network Twintide, FP7 CRISIS, Critical Incident Management Training System using an Interactive Simulation Environment, and Nordic HPC (NHPC). She has published in research journals, conference proceedings and books, reviewed for HCl conferences and journals and organized two major conferences and a number of smaller conferences and workshops. 